\title{
$\widehat{A}$ Madridge \\ madridge Journal of Case Reports and Studies \\ interconn
}

Research Article

Open Access

\section{Purse String Umbilicoplasty for Repair of Omphalocele Minor with Review of Literature}

\author{
Sarah Magdy Abdelmohsen ${ }^{1 \star}$, and Mustafa Ali Redwan ${ }^{2}$ \\ ${ }^{1}$ Assistant Lecturer, Department of Pediatric Surgery, Aswan University Hospital, Egypt \\ ${ }^{2}$ Assistant Lecturer, Department of Pediatric Surgery, Sohag University Hospital, Egypt
}

\section{Article Info}

*Corresponding author: Sarah Magdy Abdelmohsen

Department of Pediatric Surgery

Aswan University Hospital

Egypt

Tel: 002-01012069422

E-mail: sosoramily@yahoo.com Sara.magdy@aswu.edu.eg

Received: August 2, 2018

Accepted: August 22, 2018

Published: August 28, 2018

Citation: Abdelmohsen SM, Redwan MA. Purse String Umbilicoplasty for Repair of Omphalocele Minor with Review of Literature. Madridge J Case Rep Stud. 2018; 2(1): 57-62. doi: 10.18689/mjcrs-1000115

Copyright: @ 2018 The Author(s). This work is licensed under a Creative Commons Attribution 4.0 International License, which permits unrestricted use, distribution, and reproduction in any medium, provided the original work is properly cited.

Published by Madridge Publishers

\begin{abstract}
Background

Umbilicoplasty is required in the repair of omphalocele minor. The author below describes a simple, easy and safe method for the repair of the umbilicus in cases of omphalocele minor.

\section{Methods}

During the period from January 2015 to May 2017, 16 patients (11 males, 5 females) with omphalocele minor were operated by purse string technique. It is a prospective observational study with a level of evidence type 4 . One case presented by intestinal obstruction due to twisted Meckel's diverticulum. Other case presented by intestinal obstruction due to intestinal malrotation. One case the contents were the cecum and appendix. In two cases the sac contained part of the left lobe of the liver.
\end{abstract}

\section{Results}

Only six cases were diagnosed antenatally. Thirteen patients presented the same day of birth and 3 patients presented at the 3rd birthday. The sac was intact in 14 cases and ruptured in two. Two cases had hypospadias. One case had absent radius and ulna on the right hand and polydactyl on the left hand. Size of the fascial defects ranged from $2 \mathrm{~cm}$ to $5 \mathrm{~cm}$ (mean $3.5 \mathrm{~cm}$ ). Good outcomes occurred in 14 patients.

Conclusion: A good aesthetic appearance obtained when using purse string umbilicoplasty for repair of omphalocele minor.

Type of study: prospective observational study

Level of Evidence: Therapeutic type 4.

Keywords: Omphalocele; Exomphalos; Umbilicoplasty; Umbilicus; Purse string.

Abbreviation: ASD: Atrial Septal Defect; VSD: Ventricular Septal Defect; PDA: Patent Ductus Arteriosus.

\section{Introduction}

The incidence of Omphalocele is 1 per 5,000 live births; it is defined as congenital midline abdominal wall defect less than $5 \mathrm{~cm}$ in diameter, which results in herniation of intra-abdominal contents through the umbilicus [1] (Figureure 1). Umbilicoplasty is required in many conditions such as congenital absence due to bladder exstrophy, gastroschisis, omphalocele, cloacal exstrophy, traumatic umbilical malformation, and after abdominoplasty, breast reconstruction using abdominal tissues, umbilical herniorrhaphy and laparotomy [2]. Herein we described a simple technique for umbilical reconstruction in cases of omphalocele minor that looks natural in terms of location, size and easy to learn for junior surgeon. 


\section{Material and Methods}

From the period of January 2015 to May 2017, 16 patients with omphalocele minor were treated at pediatric surgery unit, Sohag and Aswan University Hospitals by two experienced pediatric surgeons. Immediate admission to the NICU, open NG tube, IV fluid and antibiotic prophylaxis were started. The preoperative preparation of the newborn, gestational age, birth weight, and other associated malformations were recorded. All patients were subjected to echocardiography, abdominal ultrasound, chest and spine x-ray to exclude other congenital anomalies. Written consents were obtained from all patients' parents before the operative intervention.

\section{Operative technique}

The operation was performed under general anesthesia. A puncture was done on one side of the sac using electrocautery. A right-angled clamp was then carefully inserted through this puncture and its blades were opened apart. The sac was excised circumferential using electrocautery, the umbilical vessels were dissected, clamped and ligated.

The contents were examined meticulously for other anomalies. Healthy intestine reduced back into the abdomen. Intestine or liver adherent to the sac was dissected carefully by sharp and blunt dissection. After complete dissection, the contents examined for injuries or other pathology and then reduced back into the abdomen. The little finger was passed circumferential around the inner edge of the defect to make sure that all adhesions have been divided (Figureure 2).

The edges of the defect were freed circumferential from the skin for a few millimeters. The fascial defect was repaired vertically using 3/0 Polypropylene sutures in an anatomical manner (Figureure 3). The umbilicus was repaired by a subcuticular $5 / 0$ vicryl purse string suture that was incorporated into the middle of the fascial closure (Figureure 4) (Figureure 13).

\section{Special cases}

One case presented with intestinal obstruction proved too had a twisted Meckel's diverticulum due to adhesion between Meckel's diverticulum and the sac, segmental resection and anastomosis was done.

Other case presented by intestinal obstruction due to intestinal malrotation (Figureure 7).

One case the contents were the cecum and appendix which appeared thick and congested so appendectomy was done (Figureure 8).

In two cases the sac contained part of the left lobe of the liver, which was adherent to the sac (Figureure $9 \& 10$ ). Dissection resulted in bleeding due to a capsular liver tear. In the first Case, a Figureure of eight stitches was taken to stop the bleeding used chromic catgut 3-0 rounded. In the second case, tear results from a direct puncture to the sac and stopped by direct compression with a gelfoam.

In two cases the contents were edematous and difficult to reduce, so the defect was enlarged upwards for a few millimeters and repaired as usual.
Postoperative, all patients were kept on IV fluids until passing stool usually within 24 hours and discharged from the hospital 24-48 hours, except for a case of resection anastomosis which kept on IV fluids for 3 days and discharged after 1 week. The antibiotic was continued for 5 days. The first dressing was 4 days postoperative. The average period of following up was 2 months.

\section{Results}

The total numbers of cases were 16 cases ( 11 males, 5 females). All babies were near term, average body weight (mean \pm SD = $2720 \mathrm{gs} \pm 174$ ). The mean operative time was 56 minutes \pm 8 . Two of the male patients had hypospadias, one subcoronal, and the other penoscrotal with marked chordate. One case had absent radius and ulna on the right arm and polydactyl on the left hand accompany by ASD, VAS, PDA (Figureure 11). There were no other associated anomalies that could contraindicate surgery or anesthesia (table 1). Only six cases were diagnosed antenatally. Thirteen patients presented the same day of birth and 3 patients presented at the 3rd birthday. The sac was intact in 14 cases and ruptured in two. Meconium was detected on rectal examination in all cases. Size of the fascial defects ranged from $2 \mathrm{~cm}$ to $5 \mathrm{~cm}$ (mean $3.5 \mathrm{~cm}$ ).

Smooth wound healing occurred in 14 patients with good outcomes. Minor complications occurred in 2 patients; one patient developed a superficial wound infection with minimal purulent discharge which responded well to conservative treatment. The other one developed a partial burst of the skin of the umbilical repair which healed gradually over 3 weeks of daily dressings; in this case, the baby weight was $2.500 \mathrm{kgs}$. and the facial defect was approximately $5 \mathrm{~cm}$. So, the repair was under tension (Figureure 12).

\section{Discussion}

The aesthetic appearance of the abdomen is directly related to good umbilical conformation [3]. Many procedures lead to a removal of the umbilicus including urachal cyst, omphalocele repair, gastroschisis repair, umbilical herniorrhaphy and tumor excision. The postoperative aesthetic results of such procedures may be aggravated by extensive scarring. Bartsich, 2003 had described a simple purse-string method for immediate umbilical reconstruction in three patients undergoing urachal cyst repairs [4].

Silvia et al, 2017 recommended umbilical cord sparing technique, but it is suitable only for omphalocele cases with small fascial defect less than $2.5 \mathrm{~cm}$ [5]. Herein, we used a purse string technique to repair omphalocele minor cases up to $5 \mathrm{~cm}$ fascial defect as these technique aids to invert the umbilical skin inwards resembling the normal umbilicus. However, we recommend another study with a larger number of cases. Table 2 showed review literature of different repair techniques for omphalocele minor.

Omphalocele minor is diagnosed prenatally in only about $50 \%$ of cases [6]. Prenatal diagnosis of gastroschisis or omphalocele is recommended to prepare for postnatal 
management at the hospital with Pediatric surgery unit, as attempts to repair the defects intrauterine have not been successful [1]. In our series, only $6 \backslash 16$ cases proved prenatal diagnosis due to infrequent follow up during pregnancy or may be due to inexperience radiologist. We had three patients presented at the 3rd days postpartum, which may be attributed to the habit of delivering at home in remote rural areas and lack of prenatal diagnosis. The sac was ruptured in two of them.

Omphalocele minor may be associated with different congenital anomalies as we review in the literature below (table 2) and in (table 1) for our series.

Care must be taken during puncture of the sac as it may contain part of the left lobe of the liver which may lead to its iatrogenic liver injury. The bleeding stops in one case by a Figureure of eight stitch suture but in the other case by direct compression with a gelfoam.

Table 1: Associated anomalies with omphalocele minor

\begin{tabular}{|c|c|}
\hline Associated anomaly & Number of cases \\
\hline Hypospadias & 2 cases \\
\hline $\begin{array}{c}\text { Absent radius and ulna on the right arm and } \\
\text { polydactyl on the left hand, ASD, VAS, PDA. }\end{array}$ & 1 case \\
\hline Meckel's diverticulum & 1 case \\
\hline Intestinal malrotation & 1 case \\
\hline
\end{tabular}

ASD: Atrial Septal Defect.VSD, Ventricular Septal Defect. PDA, Patent Ductus Arteriosus.

Figure 1: A case of an omphalocele minor

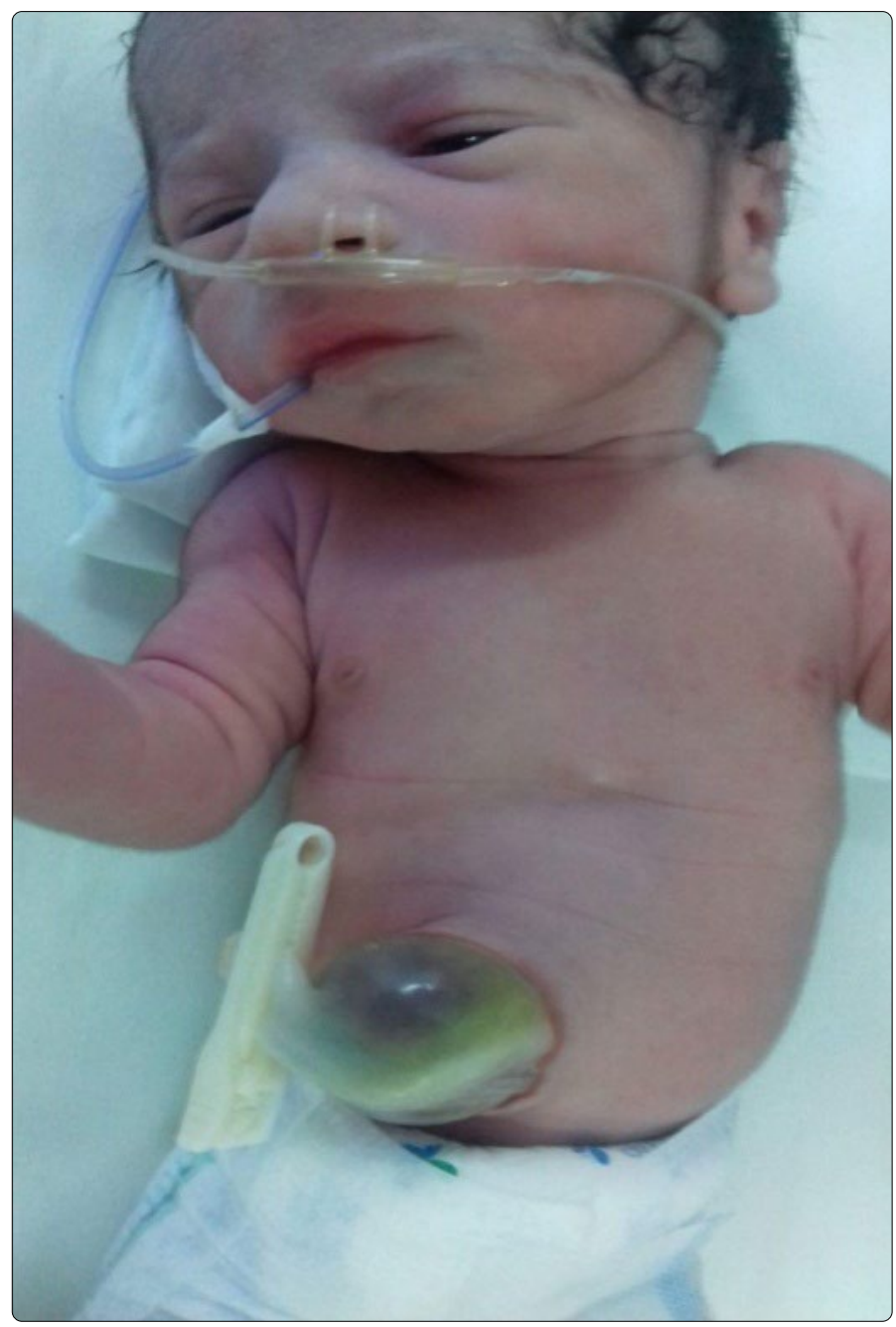

Figure 2: Defining the edge of the fascial defect and assuring release of any adhesions.

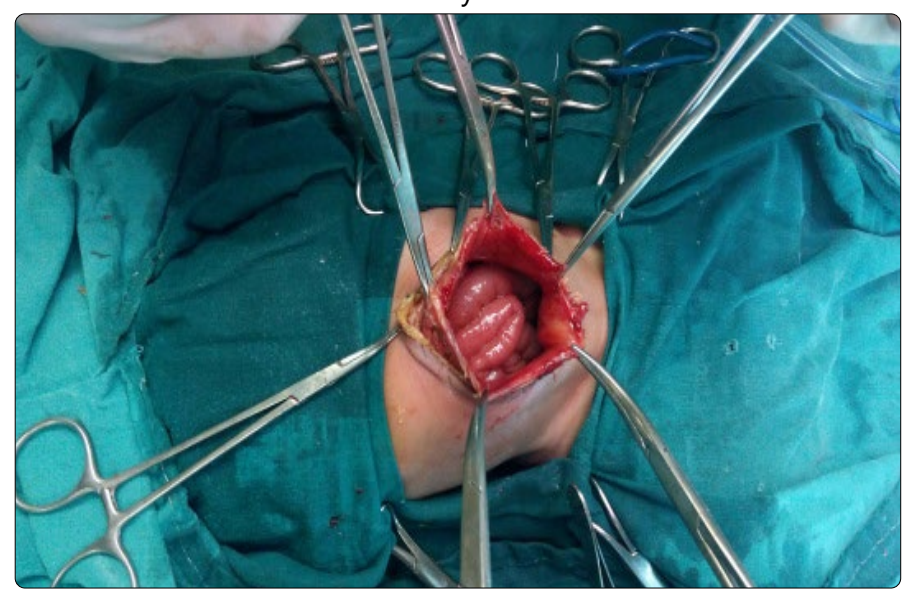

Figure 3: The fascial defect was repaired vertically.

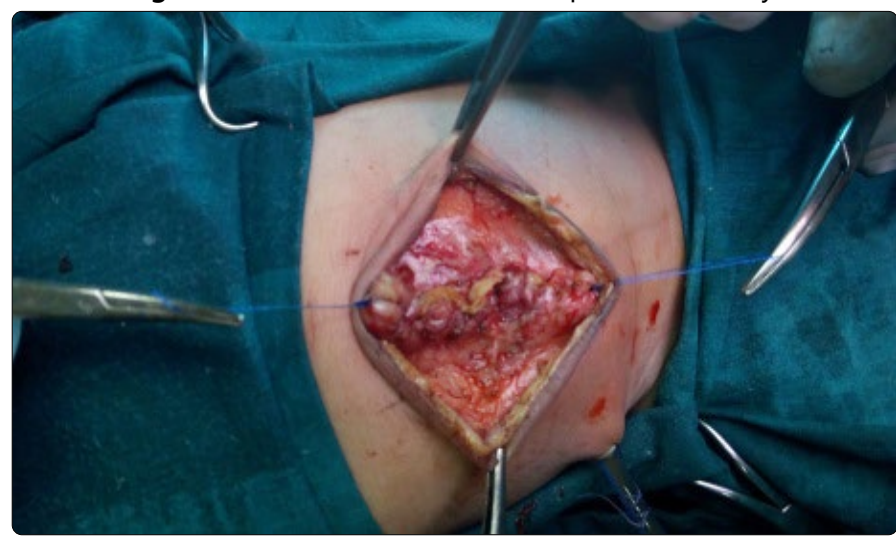

Figure 4: The umbilicus was repaired by purse- string suture. 
Figure 5: $5^{\text {th }}$ day postoperative appearance.

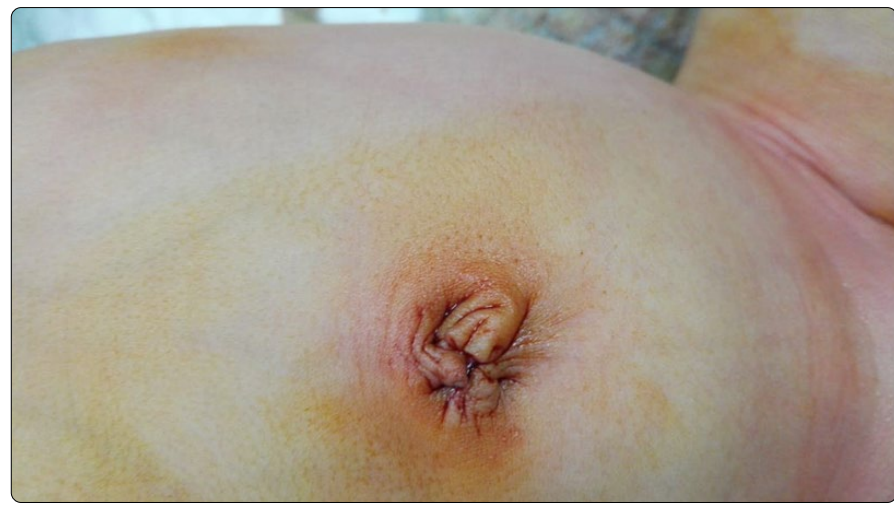

Figure 6: 2 month's postoperative appearance.

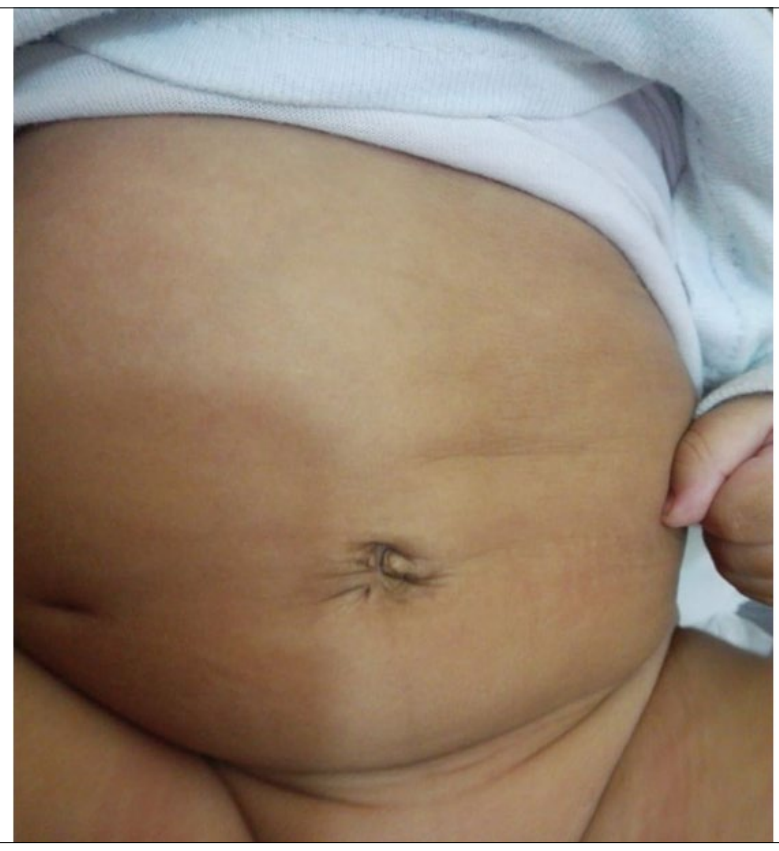

Figure 7: One case with intestinal malrotation.

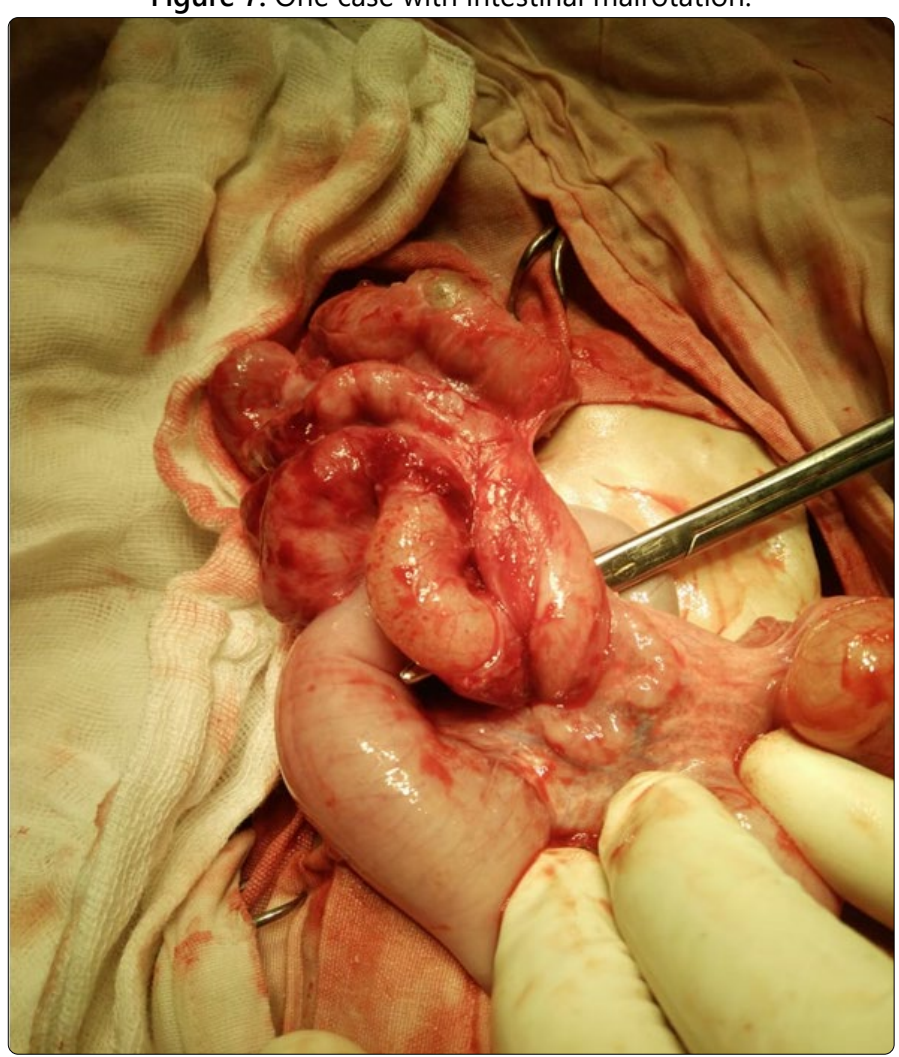

Figure 8: One case the contents were the cecum and appendix.

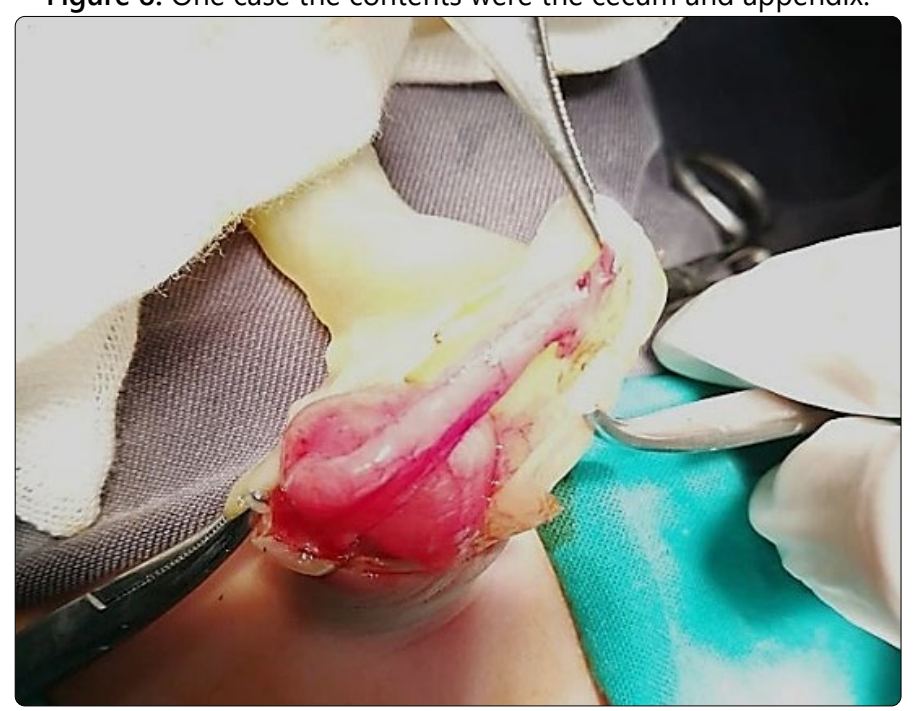

Figure. 9: One case the sac contained part of the left lobe of the liver.

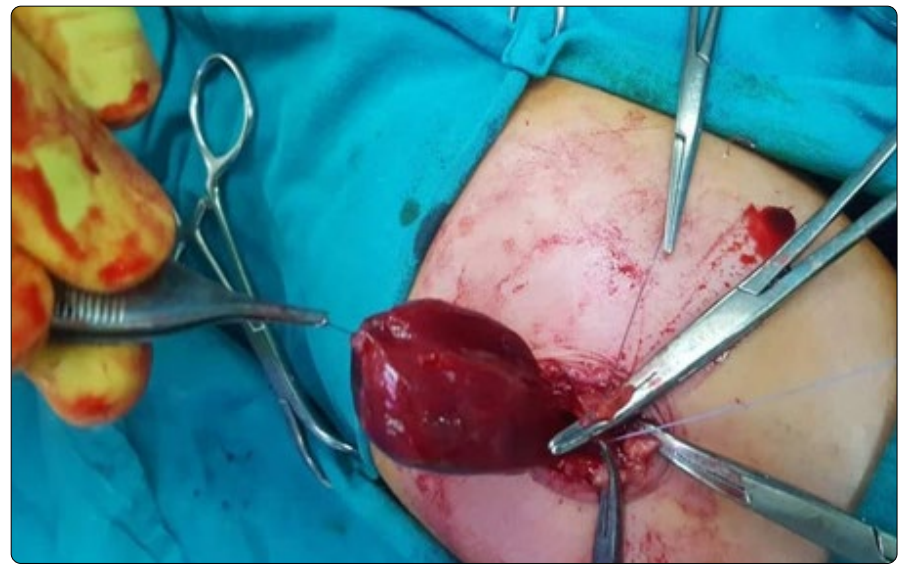

Figure. 10: another case the sac contained part of the left lobe of the liver.

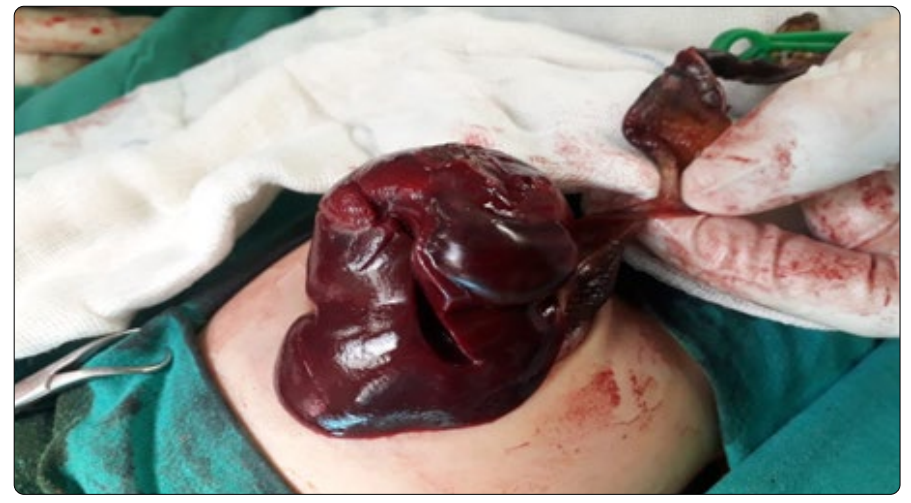

Figure. 11: One case had absent radius and ulna on the right arm and polydactyl on the left hand. 


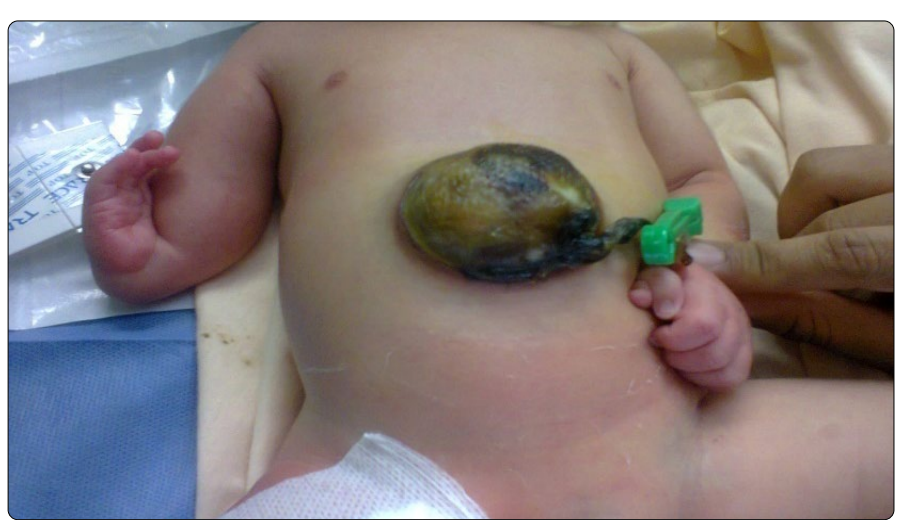

Figure 12: Umbilical skin gaping due to wound infection.

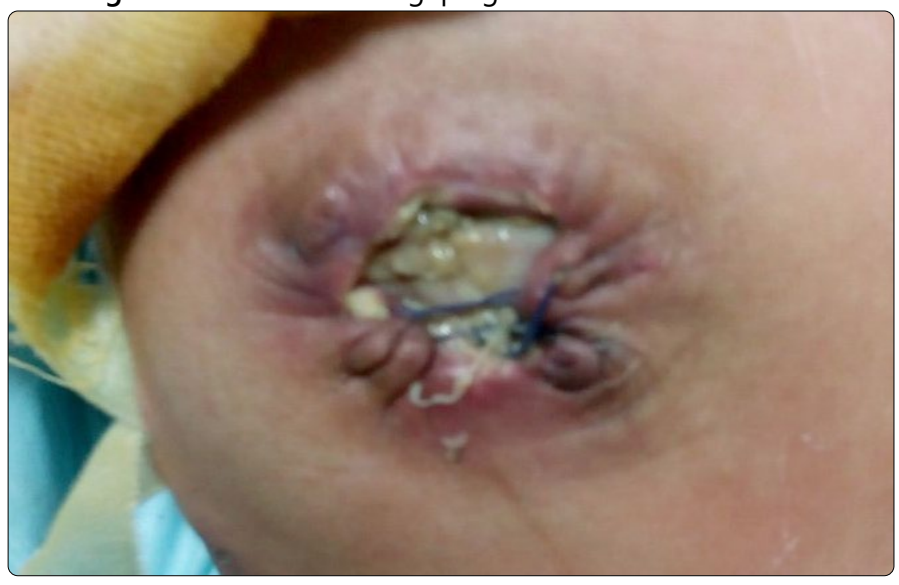

Figure 13: Purse String Umbilicoplasty technique.

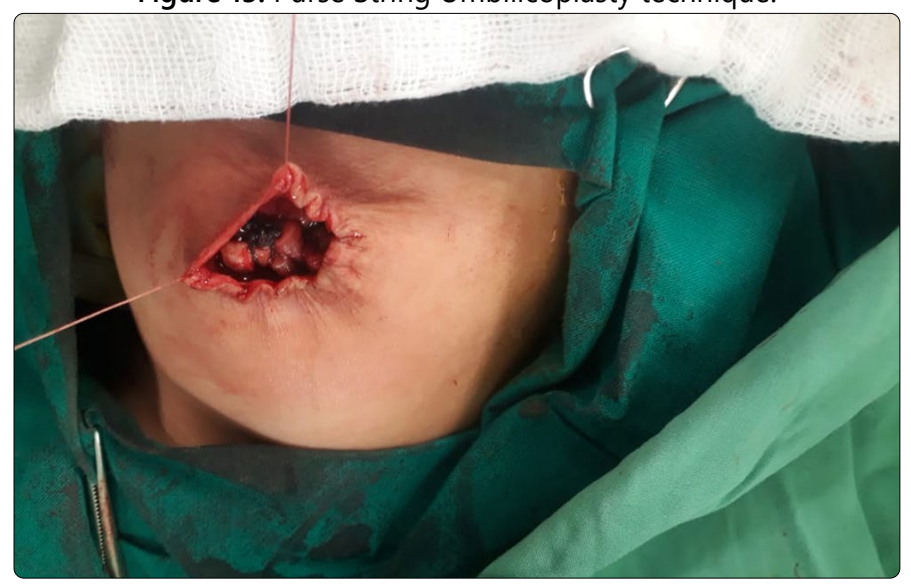

Table 2: Review literature for omphalocele minor and hernia of the cord (2009-2018).

\begin{tabular}{|c|c|c|c|c|c|c|}
\hline NO & References & $\begin{array}{c}\text { Total } \\
\text { number of } \\
\text { cases }\end{array}$ & $\begin{array}{c}\text { Number of } \\
\text { prenatal } \\
\text { diagnosis }\end{array}$ & $\begin{array}{l}\text { Number of } \\
\text { rupture sac }\end{array}$ & Associated anomaly & $\begin{array}{l}\text { Surgical technique to the } \\
\text { defect }\end{array}$ \\
\hline 1 & IBRAHIM [1] & 38 & 13 & 5 & $\begin{array}{l}\text { One patient had polydactyl and distal penile hypospadias. } \\
\text { One patient had patent vitellointestinal duct. } \\
\text { One patient had ileal atresia type } 2 .\end{array}$ & Purse string umbilicoplasty \\
\hline 2 & Silvia et al.,[5] & 8 & 5 & - & $\begin{array}{c}2 \text { cases with intestinal malrotation } \\
6 \text { cases with mild congenital heart defects[Small patent ductus } \\
\text { arteriosus or patent foramen ovale] } \\
\text { Accompany with Beckwith-Wiedemann Syndrome }(n=2) \text {, second } \\
\text { branchial cleft anomaly }(n=1) \\
\text { Hemi-hypertrophy }(n=1) \text {, Turner Syndrome }(n=1) \text {, } \\
\text { Ectopic liver }(n=1) \text {. }\end{array}$ & $\begin{array}{l}\text { Umbilical cord sparing } \\
\text { technique }\end{array}$ \\
\hline 3 & Ince et al.,[7] & 15 & 8 & - & $\begin{array}{c}\text { Four infants } \\
\text { agenesis of the right kidney, left kidney with a duplex system, } \\
\text { coarctation of the aorta, ventricular septal defect, meningocele, club } \\
\text { foot, and choanal atresia. }\end{array}$ & $\begin{array}{l}\text { The double purse-string } \\
\text { technique }\end{array}$ \\
\hline 4 & Sohn et al., [8] & 1 & 0 & 0 & Meckel diverticulum & $\begin{array}{l}\text { repaired layer by } \\
\text { layer simple repair }\end{array}$ \\
\hline 5 & Adigüzel et al., [9] & 1 & - & - & ileocecal junction atresia & - \\
\hline 6 & Mirza et al., [10] & 3 & 0 & 1 & $\begin{array}{l}\text { two cases associated with patent vitellointestinal duct (PVID) } \\
\text { One case with malrotation of the gut, (type I) atresia at proximal } \\
\text { jejunum, a } 3 \mathrm{~cm} \text { long stenosis of the ascending colon with a } \\
\text { mesenteric defect }\end{array}$ & - \\
\hline 7 & Mirza et al., [11] & 1 & 0 & 0 & congenital short gut & - \\
\hline 8 & Singh et al; [12] & 1 & 0 & 0 & patent vitellointestinal duct (PVID) & - \\
\hline 9 & Sabzehei et al ${ }_{i}[13]$ & 1 & 0 & 0 & patent vitello-intestinal duct (PVID), and Meckel's diverticulum & purse-string technique \\
\hline 10 & Ferede et al; [14] & 1 & 0 & 0 & $\begin{array}{l}\text { Congenital absence of the entire colon, } \\
\text { imperforate anus,glandular hypospadias, atrial septal defect, } \\
\text { unilateral sensorineural deafness, bilateral grade } 3 \text { vesico-ureteric } \\
\text { reflux and partial duplication of bladder, Pearson's syndrome }\end{array}$ & $\begin{array}{l}\text { Umbilicus was created with } \\
\text { purse string suture and } \\
\text { abdominal wall defect was } \\
\text { closed in layers. }\end{array}$ \\
\hline
\end{tabular}

\section{Conclusion}

The aesthetic appearance of the umbilicus after repair of omphalocele minor using purse-string method is good. Babies with omphaloceles must be examined thoroughly for other congenital anomalies. Careful inspection of the base of the umbilical cord before clamping is recommended to prevent any damage to the content in cases with missing prenatal diagnosis.

Conflicts of interest: No conflicts of interest.

\section{Consent:}

A written consent has been taken from the parents of the children for operative intervention. The article does not contain any patient information, so we do not obtain any consent from 
the parent for publication.

\section{Acknowledgment}

To Dr. Mohamed Gomaa Fouda, pediatric surgery fellow at Egyptian fellowship of pediatric surgery, Cairo University Children Hospital, for his intraoperative photo picture number 7.

\section{References}

1. Ibrahim a. Ibrahim; immediate transumbilical repair and umbilical plasty for omphalocele minor; med. J. Cairo univ. 2013; 81(1): 437-444.

2. Bayumi EK. Neoumbilical Reconstruction as an Adjuvant Procedure in Abdominoplasty. Journal of Surgery. 2016; 4(1): 16-18. doi: 10.11648/j. js.s.2016040101.14

3. Donnabella A. Anatomical reconstruction of the umbilicus. Rev. Bras. Cir. Plást. 2013; 28(1): 119-123. doi: 10.1590/S1983-51752013000100020

4. Bartsich SA, Schwartz MH. Purse-string method for immediate umbilical reconstruction. PlastReconstr Surg. 2003; 112(6): 1652-55. doi: 10.1097/01. PRS.0000086084.32830.72 